\title{
A relação família e escola em um contexto de escolarização do aluno com deficiência: reflexões desde uma abordagem sociológica figuracional
}

\section{The relationship between family and school in a context for educating students with disabilities: reflection based on a figurational sociological approach}

\author{
Reginaldo Celio Sobrinho ${ }^{1}$ \\ Edson Pantaleão Alves ${ }^{1}$
}

\begin{abstract}
RESUMO
Neste texto refletimos sobre dilemas e perspectivas na relação família e escola. Constituíram sujeitos da pesquisa os pais e os profissionais do ensino envolvidos nas atividades de um Fórum de Famílias de alunos com deficiência organizado em uma escola pública do município de Vitória/ ES. A investigação pautou-se na pesquisa-ação colaborativo-crítica e nos pressupostos da Sociologia Figuracional - elaborada por Norbert Elias. Das reflexões, destacamos que nas interdependências dos familiares dos profissionais do ensino, emergiram tensões que favoreceram, a uns e a outros, a construção de crenças mais positivas quanto à educabilidade do aluno com deficiência. Essas "novas" crenças, desde então, mobilizaram as pessoas, provocando "reagrupamentos", aproximações, afastamentos, enfim, desenharam outras relações que, por um lado, não se baseavam unicamente na formação ou ocupação profissional, nas questões de gênero, ou ainda, nas condições econômicas das pessoas envolvidas e, por outro lado, colocavam em movimento a balança de poder da relação família e escola. Observamos que, pouco a pouco, ao longo da trajetória do Fórum de Famílias de Alunos com Deficiência, as crenças dos profissionais do ensino relativas à inclusão escolar e as expectativas dos familiares acerca da escolarização de seus fi-
\end{abstract}

${ }^{1}$ Universidade Federal do Espírito Santo (UFES), Centro de Educação. Rodovia Fernando Ferrari, $\mathrm{n}^{\circ}$ 514. Goiabeiras. Vitória, Espírito Santo, Brasil. CEP: 29055-910. 
lhos concorreram para a produção de outros referentes de poder que, então, passavam a explicar os sentimentos de pertencimento e de empoderamento e também de inclusão, de escolarização, de aprendizagem e de deficiência.

Palavras-chave: relação família e escola; deficiência; inclusão; Sociologia Figuracional; balança de poder.

\begin{abstract}
In this text, we reflect on the dilemmas and perspectives of the relationship between family and school. The study subjects were parents and education professionals involved in the activities of a Forum for Families with Special Needs held at a public school in the Municipality of Vitória, ES. The investigation was based on collaborative critical action research, and figurational sociology premises as developed by Norbert Elias. From our reflections, we highlight that, in interrelations of family members and education professionals, there may be shocks that provide both sides with more positive expectations concerning the education of these students. These "new" beliefs have since then mobilized people, causing "regrouping", closeness and estrangement. In other words, they have traced other relations that were not solely based on educational background or professional occupation, on gender questions, or even on the economic situation of the people involved. On the other hand, they moved the balance of power of the family-school relation. We observed that, little by little, throughout the history of the Forum for Families with Special Needs, education professionals' beliefs concerning school inclusion and parents' expectations about their children's education led to producing other power referents which then began to explain the feeling of belonging and empowerment, and also those of inclusion, education, learning and deficiency.
\end{abstract}

Keywords: family-school relationship; disability; inclusion; Figurational Sociology; balance of power.

\title{
Introdução
}

As questões contidas neste texto se organizam em torno da temática relação família e escola. Mais especificamente, ocupamo-nos em refletir sobre dilemas e perspectivas na relação família e escola em um contexto de escolarização do aluno com deficiência, transtornos globais do desenvolvimento e altas habilidades/superdotação. Com esse propósito, estudamos aspectos da trajetória de 
um Fórum de Famílias de Alunos com Deficiência, organizado em uma escola pública municipal, considerando o período de março de 2004 até junho de 2008.

O delineamento dessa problematização emergiu, fundamentalmente, da confluência das indicações evidenciadas na literatura que versa sobre a temática relação família e escola, dos pressupostos da Sociologia Figuracional elaborada por Norbert Elias e da perspectiva teórico-metodológica da pesquisa-ação colaborativo-crítica.

Da literatura consultada extraímos algumas sínteses que problematizam o fato de, em grande parte dos casos, a relação família e escola configurar-se como uma relação assimétrica, estabelecida entre leigos e especialistas, e de organizar-se a partir de uma perspectiva escolarizada ou escolacentrada dessa relação, assegurando aos profissionais do ensino a possibilidade de categorizar, classificar e, até mesmo, escolarizar os pais dos alunos (FARIA FILHO, 2002; SILVA, 2003; DAVIES, 2005; WINESS; STANLEY, 2005).

Uma segunda questão extraída da literatura refere-se aos modos de participação e de envolvimento dos pais na escolarização de seus filhos. Para Lahire (1995) e Carvalho (1998), a ausência ou invisibilidade dos pais no espaço físico da escola não significa, necessariamente, desinteresse e descaso à escolarização dos filhos. A esse respeito, os autores destacam duas questões vinculadas entre si: a) os pais guardam expectativas extremamente positivas acerca da escolarização do filho; e b) os pais participam ao seu modo na escolarização dos filhos, e não do modo como a "escola" espera que participem.

Da perspectiva sociológica figuracional, referenciamo-nos em dois argumentos elisianos: a compreensão de que os indivíduos, em interdependências, constituem figurações que estão em permanente processo de constituição e de transformação e o entendimento de que o poder é uma ocorrência cotidiana que faz parte das relações humanas. Nesses argumentos, as noções de figuração e de equilíbrio ou balança de poder, desenvolvidas por Norbert Elias, se fizeram primordiais.

Figuração é um conceito central na elaboração teórica de Norbert Elias que, utilizando-se desse conceito, coloca as relações como ponto de partida na investigação sociológica e acentua a ideia de que os indivíduos e grupos humanos só podem existir em figurações ou em inter-relações (ELIAS, 1994).

Conforme nos esclarece o autor, uma figuração pode ser formada por um número restrito de pessoas - um casal ou um grupo de alunos -, ou por milhões delas - uma nação -, assim como pode se referir tanto a relações harmônicas, quanto a relações hostis e tensas entre as pessoas e os grupos que as formam.

Segundo Elias (2001), os seres humanos singulares se transformam nas figurações ao mesmo tempo em que transformam as figurações que eles constituem. Desse modo, ações e autores, indivíduo e sociedade são indissociáveis. 
Em outros termos, individualização e socialização são diferentes denominações que se referem a um mesmo processo.

Por meio do conceito de figuração, Elias acena para a incerteza e para imprevisibilidade das relações estabelecidas entre indivíduos e/ou grupos humanos, afinal essas relações são, necessariamente, relações de poder. Chegamos aqui em outra elaboração elisiana que contribuiu, sobremaneira, nas análises e discussões que desenvolvemos em nossa investigação: o equilíbrio (ou a balança) de poder nas relações humanas.

Diante das inúmeras e inesperadas circunstâncias sociais vividas, Elias considera o poder como elemento constituinte de qualquer relação. Em Elias toda relação é relação de poder. Segundo o autor, "[...] Desde que nasce, a criança tem poder sobre os pais, e não só os pais sobre a criança". Da mesma forma, "[...] O senhor tem poder sobre o escravo, mas o escravo também tem poder sobre o seu senhor" (ELIAS, 2005, p. 81), ainda que essas oportunidades de poder sejam distribuídas/equilibradas muito desigualmente.

Assim é que a noção de poder, desenvolvida por Norbert Elias, permite-nos superar a perspectiva que tem confinado a análise da realidade social e política à simples e imutável polaridade: dominantes e dominados ou, ainda, àquelas perspectivas que tomam o poder como algo em si-como uma coisa, como um objeto (um anel, uma bolsa) - que alguém pode guardar consigo independente da processualidade das relações estabelecidas entre as pessoas e/ou grupos humanos (ZABLUDOVSKY, 2007).

Conforme destacamos inicialmente, associada às indicações evidenciadas na literatura que versa sobre a temática relação família e escola e aos pressupostos da Sociologia Figuracional, a abordagem teórico-metodológica da pesquisa-ação colaborativo-crítica (JESUS, 2008) contribuiu no delineamento das questões que moveram nosso estudo.

Dessa abordagem teórico-metodológica, recuperamos a possibilidade e a relevância de o pesquisador mergulhar no fluxo histórico do grupo durante o trabalho de investigação (JESUS, 2008; BARBIER, 2004). Nessa perspectiva investigativa, os temas e as questões animadoras das pesquisas tomam por referência os dilemas, os desafios e as possibilidades que se presentificam no contexto social mais amplo aos quais os "sujeitos da pesquisa" estão direta ou indiretamente implicados (JESUS, 2008).

Por outro lado, essa abordagem teórico-metodológica pressupõe que, no trabalho de investigação, o pesquisador observe não apenas as decisões, as escolhas, as tentativas de mudança, mas também os movimentos de resistência e de exclusão desde uma perspectiva nós. Coerente com os pressupostos da Sociologia Figuracional, nessa abordagem teórico-metodológica o que estu- 
damos faz parte da nossa realidade; os indivíduos aos quais nos referimos em nossas descrições e análises devem ser vistos como pessoas semelhantes a nós.

Essas indicações nos ajudaram a compor algumas questões iniciais que ganharam novos significados à medida que tomávamos o Fórum de Famílias de Alunos com Deficiência, organizado em uma escola pública municipal, como lugar empírico de investigação. Mas então, o que é esse Fórum de Famílias?

A seguir, apresentamos aspectos da dinâmica e da organização do Fórum de Famílias de alunos com deficiência. Na sequência, descrevemos o nosso percurso de investigação, identificando o campo e os sujeitos envolvidos. No item seguinte, trazemos aspectos dos dados coletados e as análises decorrentes. Finalizamos o texto anunciando algumas considerações a respeito do vivido $\mathrm{e}$ construido por meio deste trabalho de investigação.

\section{Um fórum de famílias de alunos com deficiência em uma escola de ensino comum}

O Fórum de Famílias de Alunos com Deficiência instituiu-se em 2004, quando os profissionais do ensino que atuavam em uma escola pública de ensino comum explicitavam um consenso em torno da crença de que os pais de alunos com deficiência e os profissionais do ensino precisavam de um espaço de formação, de troca de experiência, bem como de elaboração e de avaliação da política educacional adotada na escola.

Desde a instituição do Fórum de Famílias, os encontros mensais ocorrem mensalmente e são registrados em ata. De modo geral, esses encontros têm início com uma mensagem seguida de breve reflexão e, na sequência, são promovidas discussões e debates em torno de temas e de questionamentos levantados no grupo. No período de 2004 a 2008, foram promovidas palestras com a participação de pesquisadores da área de Educação Especial, representantes do poder público Estadual e Municipal; relatos e conversas com pais, cujos filhos apresentavam deficiência; reuniões com os professores do serviço especializado em Educação Especial; participação dos pais em "reuniões abertas" com os profissionais que atuavam no turno matutino; discussão sobre a implementação de programas e de projetos da Secretaria Municipal de Educação relativos à escolarização dos alunos com deficiência; enfim, a realização do I e II Fórum Ampliado de Famílias de Alunos com Deficiência, o primeiro realizado em 18 de novembro de 2006 e o segundo em 27 de outubro de 2007. Nesses dois eventos buscou-se a participação de pais e de profissionais do ensino vinculados a outras 
escolas do município. Nos folders relativos a esses dois eventos encontramos os seguintes objetivos: Possibilitar o debate sobre as políticas públicas na Educação inclusiva; oportunizar o diálogo entre a comunidade escolar, famílias e pesquisadores sobre possibilidades e desafios, no contexto educacional.

O Quadro 1 apresenta a quantidade de participantes nos encontros mensais do Fórum no período de 2004 até 2008, identificando o membro da família que "representava" o aluno nesses encontros.

\begin{tabular}{|l|l|l|l|l|l|}
\hline PARTICIPANTES & 2004 & 2005 & 2006 & 2007 & 2008 \\
\hline MÃE & 12 & 14 & 09 & 31 & 15 \\
\hline PAI & 03 & 02 & 01 & 05 & 01 \\
\hline TIA & - & - & - & 01 & - \\
\hline AVÓ & - & - & 01 & 01 & - \\
\hline
\end{tabular}

QUADRO 1 - NÚMERO E IDENTIFICAÇÃO DO MEMBRO DA FAMILIA QUE PARTICIPAVA DOS ENCONTROS MENSAIS DO FÓRUM, NO PERIODO DE 2004 ATÉ 2008

É importante destacar que chegamos a esse total de participantes por ano a partir da consulta às listas de frequência dos encontros. Para efeito de totalização, consideramos uma só vez os nomes ali contidos; assim consideramos tanto os nomes dos pais que compareceram apenas uma vez, quanto àqueles familiares que mantiveram participação regular nos encontros mensais do Fórum.

Entre os familiares que participaram de maneira mais sistemática dos encontros mensais, realizados em 2007 e início de 2008, podemos citar: a $\mathrm{Sr}^{a}$ Rosi (do lar, concluiu o Ensino Médio); a Sr. ${ }^{a}$ Renata (do lar, Ensino Fundamental incompleto); a Sr. ${ }^{a}$ Tania (professora, concluiu o Ensino Superior); a $S r^{a}$ Flávia (recepcionista, Ensino Superior Incompleto); Sr. ${ }^{a}$ Sandra (do lar, Ensino Fundamental incompleto); a Sr. ${ }^{a}$ Andréia (administradora de empresa, concluiu o Ensino Médio); a Sr. ${ }^{a}$ Diva (do lar, Ensino Fundamental incompleto); a Sr. ${ }^{a}$ Luzia (vendedora, concluiu o Ensino Fundamental); a Sr. ${ }^{a}$ Armanda (do lar, Ensino Superior incompleto); a Sr. ${ }^{a}$ Joana (diarista, concluiu o Ensino Fundamental); e o Sr. Nilson (balconista, concluiu o Ensino Fundamental).

Os encontros mensais do Fórum são planejados por uma equipe de coordenação, formada por profissionais do ensino que atuavam no turno matutino da escola, e representantes dos pais participantes desses encontros. Essa equipe tem autonomia na definição das temáticas e das dinâmicas dos encontros mensais, bem como a tarefa de garantir que as demandas dos pais, explicitadas nesses encontros, sejam encaminhadas. A equipe de coordenação passou por diferentes composições no período de 2004 até 2008. Ao longo 
desse período, revezando entre si, nove profissionais do ensino e seis mães, além de dois pesquisadores, integraram essa equipe.

\section{Aspectos metodológicos: um desenho do estudo}

Desenvolvemos nosso estudo em uma escola de ensino comum pertencente ao sistema municipal de ensino de Vitória (ES). A escola atende um total de 937 alunos, distribuídos em três turnos - matutino (352 alunos), vespertino (345 alunos) e noturno (240 alunos). O bairro da escola apresenta um significativo número de desempregados e de trabalhadores em subempregos ou em atividades econômicas autônomas. Em situações muito peculiares, observam-se casos de estudantes que moram em abrigos ou obras sociais do bairro em decorrência de diferentes conflitos familiares. Registra-se que um número significativo de crianças são "adotadas" por tios, avós e vizinhos e que um elevado número de mulheres assumem a responsabilidade familiar.

A escola contava com a matrícula de alunos com deficiência e/ou transtornos globais do desenvolvimento desde 1998. Quando atuamos em contexto, em 2007 e 2008, nos três turnos da escola identificamos estudantes diagnosticados com: deficiência intelectual (10); Síndrome de Willians (02); Síndrome de Down (02); deficiência auditiva (02); deficiência visual (03); surdo-cegueira (01); deficiência física (01).

Nosso trabalho de investigação se estendeu de março de 2007 até junho de 2008, e as nossas atividades estiveram concentradas no turno matutino, às quartas-feiras, dia da semana em que eram realizadas as atividades do Fórum de Famílias - as reuniões da equipe de coordenação e os encontros mensais.

Constituíram sujeitos desta pesquisa os familiares de alunos com deficiência que participavam mais sistematicamente dos encontros mensais do Fórum (um total de 10 mães e 1 pai), os profissionais do ensino diretamente envolvidos nas atividades do Fórum, basicamente aqueles que compunham a equipe de coordenação do Fórum de Famílias (2 pedagogas, 2 professoras e o diretor escolar), uma estudante de Psicologia, que, inclusive, coordenou um "grupo de vivência" envolvendo as famílias "do fórum" ao longo de 2007, e outro pesquisador, que também realizava sua investigação naquela escola.

Considerando a intenção de resgatar o movimento do Fórum desde ano de sua instituição, construímos sua trajetória dos anos de 2004, 2005 e 2006 a partir do estudo de documentos - atas das reuniões do Fórum; ofícios expedidos e recebidos pelo Fórum; convites aos pais para os encontros mensais do Fórum; 
bilhetes ou recados enviados pelos pais justificando suas ausências nos encontros; folder(s) relativos aos eventos organizados na escola, sobretudo aqueles vinculados ao Fórum - e das entrevistas cedidas pelos "antigos" integrantes da equipe de coordenação do Fórum de Famílias.

Em termos de atuação, em 2007 e em 2008 participamos de quinze encontros mensais do Fórum de Famílias e de vinte e cinco reuniões da equipe de coordenação. Nesse período, os encontros mensais do fórum tiveram a seguinte dinâmica/organização: apresentação dos participantes e elaboração do cronograma de atividades do fórum para o primeiro semestre (MARÇO/2007); apresentação e discussão sobre a política de atendimento ao aluno com deficiência no município de Vitória/ES (ABRIL/2007); mesa redonda: $O$ trabalho clínico e o trabalho pedagógico na escola (MAIO/2007); roda de conversa com os professores especialistas em Educação Especial e aprovação das atividades do grupo de vivência: Os cinco sentidos (JUNHO/2007); apresentação e aprovação do cronograma de atividades para o segundo semestre, roda de conversa envolvendo professores das séries finais e início das atividades do grupo de vivência Os cinco sentidos (AGOSTO/2007)2 ; planejamento do II Fórum ampliado de famílias de alunos com deficiência e realização das atividades do grupo de vivência Os cinco sentidos (SETEMBRO/2007); roda de conversa envolvendo professores das séries iniciais e atividades do grupo de vivência Os cinco sentidos (OUTUBRO/2007); avaliação das atividades desenvolvidas no II Fórum ampliado de famílias e discussão sobre a inserção dos alunos com deficiência no Programa Educação em tempo integral (NOVEMBRO/2007); avaliação das atividades desenvolvidas pelo Fórum em 2007 e planejamento para 2008 (DEZEMBRO/2007); discussão sobre a inserção dos alunos com deficiência no Programa Educação em tempo integral e sobre o processo de sistematização do currículo da escola (MARÇO/2008); estudo sobre "adaptação curricular e/ou currículo inclusivo" (ABRIL/2008); definição sobre o revezamento dos encontros mensais do Fórum entre os turnos matutino e vespertino da escola e discussão sobre a inserção dos alunos com deficiência no Programa Educação em tempo integral (MAIO/2008); primeiro encontro mensal do Fórum, no turno vespertino e discussão sobre a inserção dos alunos com deficiência no Programa Educação em tempo integral (JUNHO/2008).

Na nossa percepção, "olhar" esse movimento a partir da perspectiva elisiana nos ajudou a compreender que, para a pessoa comprometida com a ação " $d e$ dentro" do fluxo, suas decisões assemelham-se a um rio que, apesar de seguir em direção ao mar, "[...] não encontra diante de si um leito fixo, previamente ordenado e sim um amplo terreno em que tem que buscar um curso definido"

\footnotetext{
2 Em agosto de 2007, realizamos dois encontros do fórum. Início e fim do mês.
} 
(ELIAS, 1994, p. 46). Afinal, em Elias, a história e a sociedade não são uma obviedade ou "[...] um sistema de alavancas mecânicas e de automatismos de ferro e aço, e sim, um sistema de pressões exercidas por pessoas vivas sobre pessoas vivas" (ELIAS, 1994, p. 47).

Considerando as questões que moveram nosso estudo, no próximo item tomamos o Fórum de Famílias de alunos com deficiência e escola como uma figuração específica e discutimos uma das temáticas que, constituindo-se em alvo de preocupação nos encontros mensais realizados no período de 2004 a 2008, expressam tensões que caracterizam a relação família e escola, qual seja, como ampliar a participação e o envolvimento dos demais profissionais do ensino nos encontros mensais e nas atividades do Fórum.

\section{O Fórum de Famílias como espaço de participação de pais e de profissionais do ensino}

Iniciemos com um diálogo que, imediatamente, nos coloca perante a um dilema vivido no grupo durante nossa investigação: "O Fórum de Famílias seria também um lugar de atuação e de participação dos profissionais do ensino?"

No encontro mensal, realizado em março de 2008, contávamos com quatro mães, dois pesquisadores, dois estagiários curriculares ${ }^{3}$, uma pedagoga, duas professoras do ensino comum e duas professoras do serviço especializado ${ }^{4}$. Logo no início do encontro, quando se apresentava ao grupo, a $\mathrm{Sr}^{a}$ Renata $^{5}$ destacou: [...] espero que este ano seja melhor, porque no ano passado tinha mais professores que pais. Porque eu acho que é a gente que tem que participar. Na sequência, a Sr. ${ }^{a}$ Andréia respondeu: [...] pra mim aqui somos um grupo de pessoas preocupadas com o ensino do aluno com necessidades especiais. Um pouco mais à frente, a professora Lena voltou à questão trazida pela $\mathrm{Sr}^{\mathrm{a}}{ }^{\mathrm{R}}$ Renata.

[...], pois é, isso que a Sr. ${ }^{a}$ Renata falou é importante a gente conversar na equipe de coordenação. Tem muito professor aqui. Será que isso não acaba inibindo os pais? O Fórum não é de famílias? Não deveríamos ter mais famílias do que professores? [...] Então muda o nome do Fórum!

\footnotetext{
${ }^{3}$ Estagiários que cumpriam atividades relativas à sua formação em Pedagogia.

${ }^{4}$ Professoras responsáveis pelo atendimento educacional especializado aos alunos com deficiência matriculados na escola.

${ }^{5}$ Ao longo do texto utilizamos nomes fictícios.
} 
Questões como essas nos parecem extremamente interessantes quando o foco de reflexão é a relação família e escola. Essas questões se tornam mais instigantes à medida que consultamos as atas dos encontros realizados e observamos que, em vinculação com um conjunto de transformações sociais mais amplas relativas à escolarização de alunos com deficiência, ao longo dos anos de atividades, os participantes do Fórum evidenciavam um significativo interesse de que os professores participassem de seus encontros mensais.

Retornemos, então, às atas das reuniões realizadas, especificamente nos anos de 2004 e 2005, e vejamos como se davam essas solicitações e indicações dos participantes do fórum bem como as "respostas" dadas pela "escola" a essas solicitações.

Na primeira reunião do "Fórum de Famílias de Alunos com Deficiência" ocorrida em abril de 2004, embora a ampliação do número de participantes não aparecesse como ponto de pauta, os participantes [...] pediram também que a diretora, os professores e pedagogos(as) participassem de algumas (reuniões). Ainda naquele encontro, [...] a Sr Diva levantou a possibilidade de estudantes do curso de pedagogia que possuem filhos com Necessidades Educativas Especiais participarem dos encontros do Fórum.

No segundo encontro, ocorrido em maio daquele mesmo ano, o grupo justificava a importância da participação dos professores nos encontros mensais do Fórum:

[...] os pais apontaram a ideia de que os professores deveriam participar alternadamente destas reuniões relatando as dificuldades, a maneira de trabalhar com seus filhos, isto ajudaria a compreender melhor a posição do conhecimento dos filhos. Esta atitude de colaboração auxiliaria no crescimento pessoal das crianças e no melhor acompanhamento por parte dos pais. Foi ressaltado a importância dessa troca entre escola e família.

Sob essa expectativa, tivemos o seguinte encaminhamento: [...] Os professores que estiverem em planejamento serão convidados a participarem.

Mas, ainda assim, os professores permaneciam distantes dos encontros mensais do Fórum e das questões que eram discutidas ali. No mês de dezembro de 2004, os participantes do Fórum fizeram uma avaliação das ações que vinham desenvolvendo e, naquele momento, foi destacada a falta de divulgação do Fórum na própria escola. Para o ano seguinte, os participantes [...] reivindicaram uma representação da escola nas reuniões mensais do Fórum e indicaram a 
possibilidade de um [...] rodízio entre os professores dando oportunidade a todos para participarem.

Ao longo de 2005, os participantes continuavam lamentando a ausência de contatos com os professores nos encontros mensais do Fórum. Assim, em junho de 2005, além de indicarem a necessidade de mais palestras nos encontros, os participantes do fórum solicitaram [...] uma reunião com o novo diretor e o CTA da escola. Mais tarde, em agosto de 2005, novamente o grupo convencionou a necessidade de

[...] convidar alguns professores para ampliar o conhecimento destes em relação ao trabalho inclusivo realizado na Unidade Escolar. [...] para findar o diretor pediu a palavra e sugeriu transformar, ampliar, fortalecer este Fórum para um Fórum da escola (todos os turno) para que aconteça maior legitimidade, aceitação e crescimento do projeto.

Em dezembro daquele ano, quando avaliavam as ações do fórum, os participantes voltaram a destacar [...] a pouca ou insuficiente divulgação do Fórum para os funcionários da escola [...]. Ainda em avaliação, indicaram a necessidade de possibilitar a participação dos funcionários da escola nos encontros mensais do Fórum ao longo do ano seguinte.

O primeiro encontro mensal de 2006 aconteceu, no entanto, somente em junho. Naquela ocasião, foi novamente discutida a necessidade de dar maior visibilidade ao Fórum no contexto da escola. Em atendimento a esse objetivo, o grupo apoiou a iniciativa de a "escola" realizar o "I Fórum Ampliado de Famílias de Alunos com Deficiência" ao final do ano.

Neste estudo, verificamos uma possibilidade de participação dos pais na escolarização de seus filhos: o Fórum de famílias de alunos com deficiência. E, nesse processo específico de participação, observamos a persistente solicitação dos pais em conhecer as dificuldades no trabalho docente, em ouvir os professores de maneira que pudessem ajudar os filhos no processo de escolarização. Mas, paradoxalmente, vimos um "afastamento" desses profissionais, expresso, de certa forma, na resistência em "falar" com o grupo durante os encontros mensais do Fórum. Dizemos paradoxalmente considerando o fato de, em um aspecto mais amplo da relação família e escola, os profissionais do ensino se queixarem do "desinteresse" ou da falta de apoio familiar às questões escolares dos filhos e de insistirem na necessidade de um estreitamento de relações por meio de um contato físico com os pais dos alunos pela via da promoção de reuniões de pais e/ou de assembleias, por exemplo. 
Esses dados também nos permitem inferir que as expectativas da Sr. ${ }^{a}$ Renata e as indicações da professora Lena quanto ao significativo número de professores em um Fórum de Famílias, destacadas inicialmente, revelam dilemas vividos em contextos onde a "escola" busca um estreitamento com os familiares de seus alunos. Outros estudos nos ajudam a verificar a complexidade desse processo. Vejamos.

De acordo com Silva (2003), os pais consideram o corpo docente como o principal interlocutor da relação família e escola. Em uma das três escolas que acompanhou, designadamente aquela que, ao longo do seu estudo, iniciara a organização de uma Associação de Pais, deixando a cargo dos próprios familiares a condução do "movimento", Silva (2003) observou que os pais compareciam menos à reunião da Associação de Pais e mais às reuniões e atividades propostas pela escola, e justificavam o fato argumentando que, caso as professoras não estivessem no encontro da Associação de Pais, o que eles iriam fazer lá? Acreditavam que não haveria assuntos importantes a tratar.

Na nossa investigação, também era perceptível a expectativa dos pais em encontrar-se com os professores. Mas, para além desse desejo, a coordenação e organização daquele movimento "de pais" pelos profissionais do ensino era algo aceito pelas famílias, sem restrições. Uma aceitação que se refere também ao processo histórico de invenção e de construção da educação escolar em nossas sociedades ocidentais. Adotando a noção de balança de poder, desenvolvida por Elias e Scotson (2000), é possível notar nessas circunstâncias um processo de complementaridade nós-eles.

A esse respeito, Elias e Scotson (2000) destacam que quando em uma figuração a diferença de poder entre indivíduos ou grupos chega ao extremo, os inferiores terminam por submeterem-se à avaliação que os mais poderosos lhes atribuem. Assim, o grupo mais poderoso tem a possibilidade de intervir no processo histórico da figuração que forma com os outros, de modo que a História dos inferiores - eles - pode ser construída pelo grupo majoritário - nós.

Considerando as situações vividas em nossa investigação, observamos que, em muitos aspectos, a relação família e escola se dá pela via da complementaridade nós-eles. Por meio dessa complementaridade, nós - da escola - temos a possibilidade de narrar e de determinar modos de participação e de envolvimento dos pais na escolarização dos filhos, retirando-lhes a possibilidade de narrar modos específicos de atuação nesse processo. Por essa via é que naturalizamos a relação família e escola desde uma perspectiva escolarizada dessa relação.

Mas, conforme Elias e Scotson (2000), dependendo da natureza dos vínculos, as tensões vividas nas interdependências podem impulsionar a emersão de outros referentes de poder, evidenciando um vínculo duplo menos extremo na inter-relação. Observamos essa situação quando, por exemplo, na figuração "fórum e escola", as solicitações dos pais em encontrar com os professores pas- 
savam a ter alguma importância para a escola. Nesse caso, a interdependência de pais e profissionais do ensino começava a funcionar mais abertamente e, então, gradativamente, a balança de poder, naquela figuração específica, entrava em movimento. Vivenciamos aspectos mais evidentes desse processo em 2007 e 2008, quando atuamos em contexto.

De fato, em 2007, a participação dos professores nos encontros mensais do Fórum foi buscada com maior evidência e contava, inclusive, com o apoio da equipe de gestão escolar. Assim, para o terceiro encontro, em maio de 2007, organizado sob a dinâmica de mesa redonda, duas professoras e as profissionais do serviço de apoio especializado em Educação Especial participaram dos debates. A participação de outros profissionais da escola voltou a ocorrer no quarto encontro mensal do Fórum de Famílias, em junho de 2007, quando organizamos uma roda de conversa com os profissionais do serviço de apoio especializado em Educação Especial.

Em agosto de 2007, as professoras Márcia e Eva ${ }^{6}$ participaram das atividades do sexto encontro do Fórum. Em mais duas oportunidades, os professores do ensino comum estiveram presentes. Ainda em agosto, aconteceu a segunda roda de conversa envolvendo os professores das séries finais do Ensino Fundamental e, em setembro, realizamos a terceira roda de conversa, dessa vez com os professores que atuavam nas séries iniciais do Ensino Fundamental.

A professora Márcia voltou a participar dos encontros realizados em novembro e dezembro de 2007 e em três encontros em 2008 (março, abril e maio). Também destacamos a realização do II Fórum Ampliado de Famílias de Alunos com Deficiência, realizado em outubro de 2007. A baixa frequência dos profissionais do ensino nesse evento foi bastante lamentada no encontro mensal que se seguiu a ele.

Durante as avaliações, a Sr. ${ }^{\mathrm{a}}$ Tânia deu-nos evidência quanto à necessidade de os professores se aproximarem mais das preocupações e discussões do Fórum: [...] o que eu percebo é que a escola oferece momentos de formação, momento de aprendizagem [...] Os professores falam que não sabem como trabalhar com alguns alunos, e quando a escola oportuniza discussão sobre o assunto alguns profissionais não participam.

De acordo com Elias (1993), a natureza dos vínculos estabelecidos entre os indivíduos dá às figurações uma direção específica que, ao longo do tempo e no fluxo das tensões vividas, sustenta e legitima - mas também pode fazer diminuir e/ou desaparecer - determinadas crenças, valores e sentidos atribuídos a aspectos da vida em sociedade.

${ }^{6}$ A professora Márcia - disciplina de Arte - atuava com alunos de todas as series do Ensino Fundamental. A professora Eva era professora especialista da área de deficiência visual. 
Nessa linha de análise, observamos que, naquele contexto escolar, as relações estabelecidas entre os pais e os profissionais do ensino que participavam mais sistematicamente das atividades do fórum traduziam um permanente movimento de produção e de reprodução social de distribuição de chances de poder na figuração que formavam. Mesmo que as oportunidades de poder permanecessem distribuídas desigualmente.

Nesse movimento, notamos que a participação mais direta de alguns profissionais nas atividades do Fórum de Famílias em 2007 - por exemplo, os membros da equipe de gestão escolar e as duas professoras do ensino comum - remodelava os comportamentos e desejos dos "pais" e desses mesmos profissionais. Novos referentes de poder passavam a fundamentar a relação família e escola.

Assim, em 2007, sob a coordenação desses profissionais e da Sr. ${ }^{\text {a Tânia }}$ - que então assumira uma significativa margem de poder na equipe de coordenação do Fórum -, os demais professores eram convocados a comparecer aos encontros mensais. É que o Fórum se constituía num movimento de famílias que pretendiam a participação e o envolvimento dos professores em suas atividades.

$\mathrm{Na}$ nossa percepção, as indicações dos pais a esse respeito revelam uma absoluta pertinência. A participação dos professores nesses espaços é primordial, sobretudo porque ali, mesmo que não diretamente, são debatidas questões concernentes às aprendizagens dos alunos. Nesse sentido, se os professores não veem algumas questões relativas à natureza dos vínculos que a "escola" estabelece ou pretende estabelecer com os pais, assim como as percepções e crenças acerca daqueles que "podem" aprender, precisam ser mais bem refletidas por nós, "da escola".

\section{Sobre o vivido/construído: margens e continuidades...}

Participando dos encontros mensais do Fórum de Famílias em 2007 e início de 2008 e acessando as atas dos encontros realizados entre 2004 e 2006, foi possível observar a gradativa emergência da crença de que os encontros mensais pudessem se constituir em um espaço favorável às reinvidicações para a melhoria no processo de escolarização dos alunos com deficiência. Assumindo o argumento elisiano de que os seres humanos singulares se transformam nas figurações ao mesmo tempo em que transformam as figurações que eles constituem, observamos que, pouco a pouco, o vínculo duplo estabelecido entre os pais e os profissionais do ensino tornava-se menos extremo, balizando a construção de novas expectativas, e, então, a "escola" passava a ser questionada do ponto de vista de sua competência para bem educar. 
Sem um "o que fazer" mais evidente, era recorrente a solicitação dos pais de que outros professores e a equipe técnica estivessem nos encontros mensais do fórum para esclarecer as dificuldades, as ações e o crescimento escolar do aluno com deficiência.

Do "diálogo" estabelecido entre o Fórum e a escola em torno dessa solicitação, destacamos que, embora não devamos incorrer em generalizações, precisamos colocar em questionamento o decantado desinteresse e/ou despreparo dos pais em participar dos processos educativos de seus filhos com deficiência, bem como a crença de que esses pais precisam ser "assistidos", já que são os marginalizados que trazem uma fisionomia destoante da sociedade geral. É preciso termos em conta que os pais pensam, desejam e planejam a inclusão, e não apenas respondem às ordens jurídicas e às políticas públicas relativas a esse movimento social de maneira específica e diferenciada.

No fluxo desses desejos, tensões específicas e muito diferenciadas são vividas na teia das relações que esses pais estabelecem com os profissionais do ensino que lidam com seus filhos, afinal, os profissionais trazem expectativas muito específicas e diferenciadas das dos pais e, também, entre si.

Finalmente, a partir do vivido e do construído neste processo de investigação, explicitamos nossa crença de que, nas inter-relações dos familiares de alunos com deficiência e dos profissionais do ensino, podem emergir tensões que favoreçam a construção de expectativas mais positivas quanto à educabilidade do aluno com deficiência. Essas "novas" expectativas, desde então, mobilizam as pessoas, provocam "reagrupamentos", aproximações, afastamentos, enfim, desenham outras relações que, por um lado, não se baseiam unicamente à formação ou à ocupação profissional, às questões de gênero, ou ainda, às condições econômicas das pessoas envolvidas e, por outro lado, colocam em movimento a balança de poder da relação família e escola. É que no fluxo das tensões, outros referentes de poder passam a explicar os sentimentos de pertencimento e de empoderamento, mas também de inclusão, de escolarização, de aprendizagem e de deficiência.

\section{REFERÊNCIAS}

BARBIER, René. A pesquisa-ação. Brasília: Liber Livro Editora, 2004.

CARVALHO, Maria Isabel Gonçalves. Escola/família, relação sentida e relação sonhada: estudo de caso em contexto multicultural. 190 f. Dissertação (Mestrado em Ciências 
da Educação) - Faculdade de Psicologia e de Ciências da Educação, Universidade de Lisboa, 1998.

DAVIES, Don. Além da parceria: a necessidade do activismo cívico independente para promover a reforma da escola urbana nos Estados Unidos da América. In: STOER, Stephen R.; SILVA, Pedro. Escola-familia: uma relação em processo de reconfiguração. Porto: Porto Editora, 2005.

ELIAS, Norbert. O processo civilizador: Formação do Estado e civilização. Rio de Janeiro: Zahar, 1993. v. 2.

. A sociedade dos indivíduos. Rio de Janeiro: Zahar, 1994.

. A sociedade de Corte. Investigação sobre a sociologia da realeza e da aristocracia de corte. Rio de Janeiro: Zahar, 2001. Introdução à sociologia. Lisboa: Edições 70, 2005.

ELIAS, Norbert; SCOTSON, John L. Os estabelecidos e os outsiders: sociologia das relações de poder a partir de uma pequena comunidade. Tradução: Vera Ribeiro. Rio de Janeiro: Jorge Zahar, 2000.

FARIA FILHO, Luciano Mendes. Na relação escola-família, o aluno como educador: um olhar sobre a escola nova em Minas Gerais. In: GONDRA, José Gonçalves (Org.). História, infância e escolarização. Rio de Janeiro: 7 Letras, 2002. p. 81-96.

JESUS, Denise Meyrelles. O que nos impulsiona a pensar a pesquisa-ação colaborativo-crítica como possibilidade de instituição de práticas educacionais mais inclusivas? In: BAPTISTA, Cláudio Roberto; CAIADO, Kátia Regina Moreno; JESUS, Denise Meyrelles de (Orgs.). Educação Especial: diálogo e pluralidade. 1. ed. Porto Alegre: Mediação, 2008.

LAHIRE, Bernard. Sucesso escolar nos meios populares: as razões do improvável. São Paulo: Ática, 1995.

SILVA, Pedro. Escola-família, uma relação armadilhada: interculturalidade e relações de poder. Porto: Edições Afrontamento, 2003.

WINESS, Michael G.; STANLEY, John. A reconstrução das relações escola-família, concepções inglesas de "pai responsável”. In: STOER, Stephen R.; SILVA, Pedro. Escola-familia: uma relação em processo de reconfiguração. Porto: Porto Editora, 2005.

ZABLUDOVSKY, Gina. Norbert Elias y los problemas actuales de la sociologia. México: FCE, 2007.

Texto recebido em 25 de fevereiro de 2013.

Texto aprovado em 11 de junho de 2013. 